\title{
Correlative Microscopy of Diverse Filamentous Microfossils from 850 Ma Rocks
}

\author{
David Wacey $^{1}$, Martin Saunders ${ }^{1 *}$, Andrew McPherson ${ }^{2}$, Sarah Gain ${ }^{1}$, Eva Sirantoine ${ }^{1}$ and Kate Eiloart ${ }^{1}$ \\ 1. Centre for Microscopy, Characterisation and Analysis, The University of Western Australia, Perth, \\ Australia. \\ 2. Geoscience Australia, Canberra, Australia. \\ * Corresponding author: Martin.Saunders@uwa.edu.au
}

The study of ancient fossilised life, in particular organic-walled microfossils preserved 3-dimensionally in minerals such as quartz (cherts) has seen a revolution in the past decade. Techniques such as FIBmilling combined with SEM, TEM, Raman, and NanoSIMS, have permitted targeted analysis of fossils in situ within the rocks in which they were preserved. The resulting high resolution images and chemical maps aid in the identification of intracellular features, wall ultrastructure, and non-biological artefacts which were not previously identifiable by lower resolution methods [1-2].

The 850 Myr Bitter Springs Group from Central Australia is renowned for its exquisitely preserved microfossils [3], many of which retain remnants of sub-cellular structures. A diverse assemblage of filamentous and coccoidal microfossils are present and several of these have been used as baselines in the evaluation of much older, often controversial, potential microfossils. The Bitter Springs fossils were studied intensively in the 1960's and 1970's and were the focus of some of the earliest TEM work on chemically extracted ancient microfossils [4]. However, little work has been done since due to the position of the fossil localities within culturally sensitive areas. We have recently carried out a comprehensive collection of new fossiliferous material, in consultation with local indigenous communities, and can now provide GPS data for the historical type localities plus several new localities.

Using a correlative suite of techniques including FIB-TEM, STEM-EDS, 3D-FIB-SEM, Raman, NanoSIMS and light microscopy, this contribution provides detailed analysis of the cellular ultrastructure of up to eight separate genera of $850 \mathrm{Ma}$ filamentous microfossils. It also provides nanoscale chemical information from both the organic material of the organisms and the minerals that fossilised them.

The filamentous microfossils are shown to have variable quantities of cell contents preserved. Some comprise box-like cells with $\mathrm{C}, \mathrm{S}$ and N-rich organic walls that are almost entirely infilled by microcrystalline quartz (Fig. 1). Others, however, retain significant organic material interior to the cell walls, which has been displaced around the boundaries of quartz grains as they crystallised within the cell. The most complex of the filaments appear to preserve multiple rows of cells within an enclosing membrane (Fig. 2) although some of this substructure may have been modified by quartz grain growth. All of the filaments retain a strong calcium signal whose distribution roughly corresponds to that of the cellular organic material (Figs. 1-2). However, on closer examination the distributions of Ca and organic material do not perfectly correlate, nor does $\mathrm{Ca}$ correlate with oxygen (i.e. it is not present in these areas as a carbonate mineral). This suggests that Ca may be bound to the periphery of the organic material, supporting a hypothesis that calcium binding may protect organic material from further decomposition and thus aid exceptional microfossil preservation. 


\section{References:}

[1] D Wacey et al., Precambrian Research 220-221 (2012), p. 234.

[2] MD Brasier et al., PNAS 112 (2015), p. 4859.

[3] JW Schopf, Journal of Paleontology 42 (1968), p. 651.

[4] DZ Oehler, Journal of Paleontology 50 (1976), p. 90.

[5] The authors acknowledge funding from the Australian Research Council via a Future Fellowship to DW, plus the Microscopy Australia facility at The University of Western Australia.

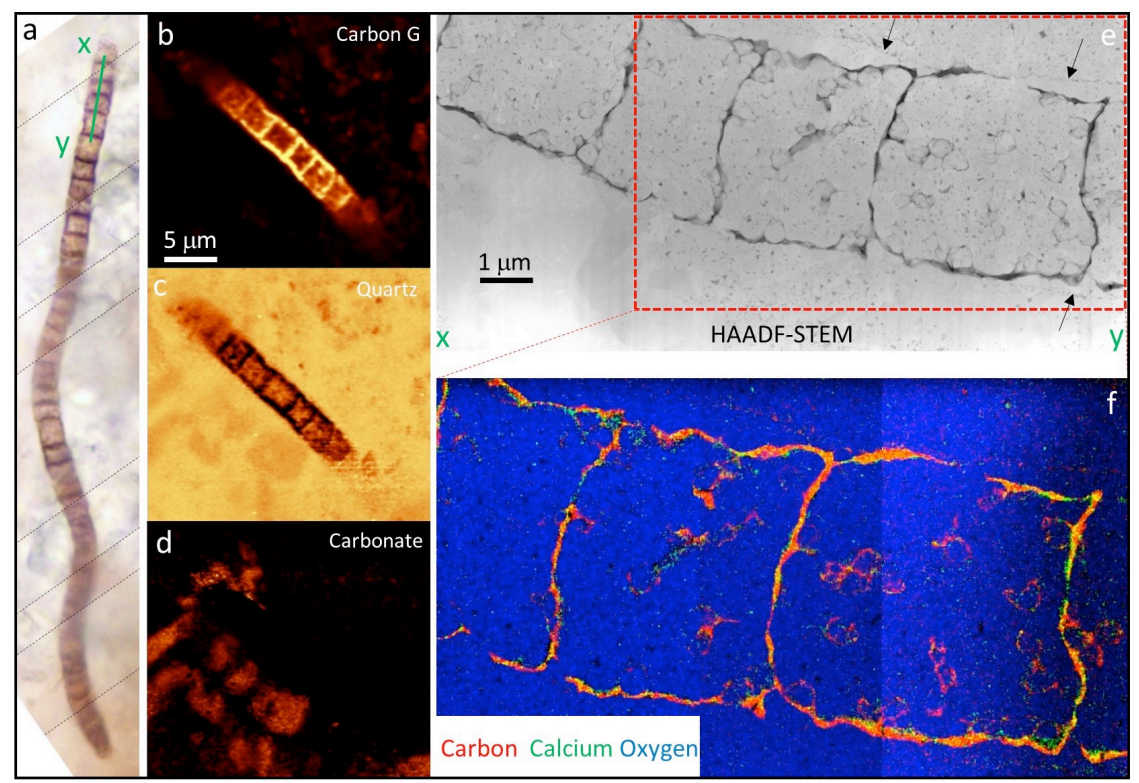

Figure 1. Correlative light microscopy (a), Raman (b-d) and TEM (e-f) analysis of a Cephalophytarion $s p$. filamentous microfossil from the Bitter Springs Group. Arrows in (e) point to fine sheath surrounding the box-like cells.

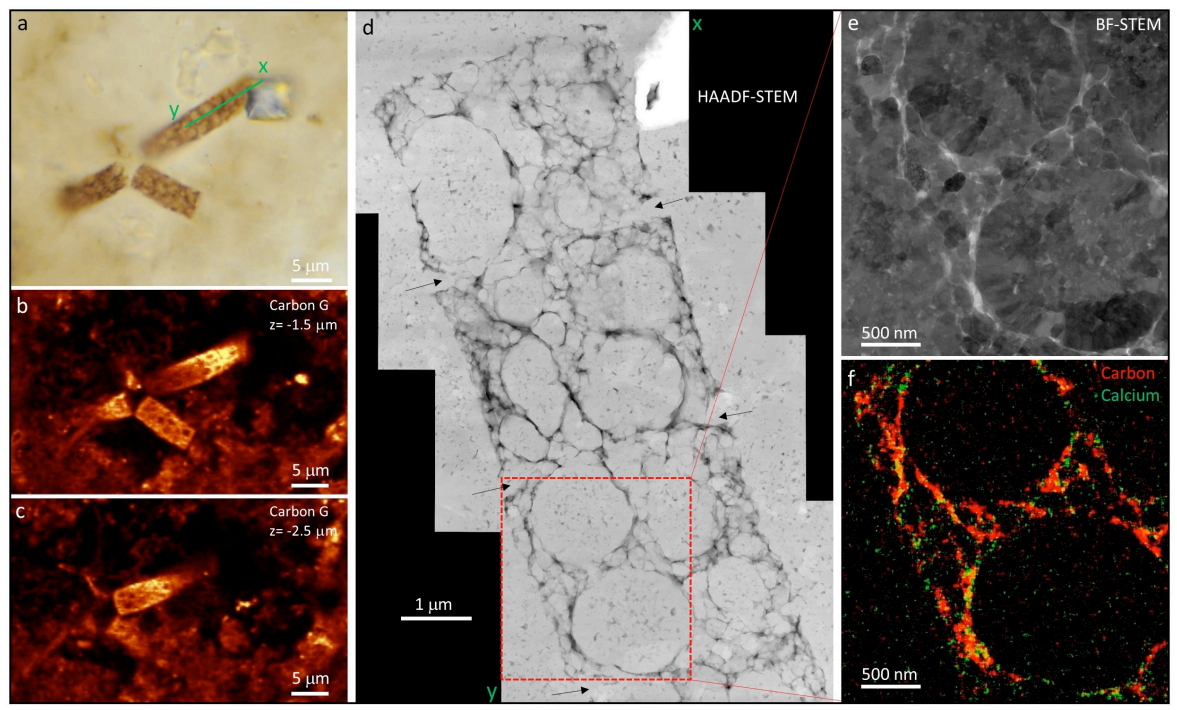

Figure 2. Correlative light microscopy (a), Raman (b-c) and TEM (d-f) analysis of newly discovered filamentous cyanobacterial microfossils from the Bitter Springs Group. Arrows in (d) point to potential segmentation of the filament. 